\title{
De-escalation of antiplatelet therapy an approach to improve safety and efficacy of treatment in patients after acute coronary syndrome
}

Dual antiplatelet treatment (DAPT) with aspirin and P2Y12 inhibitor - clopidogrel has been shown to reduce the risk of ischaemic events in patients after acute coronary syndrome (ACS) [1-3]. Further studies proved the superiority of ticagrelor and prasugrel over clopidogrel in this clinical setting [4-6]. It has been also demonstrated that prolongation of DAPT over one year with lower doses of P2Y12 inhibitor may further improve clinical outcome in patients with previous ACS [7]. At the same time significant improvement in the technology of stents and implantable scaffolds, including design, materials, and antiproliferative agents, occurred resulting in the reduction of thrombogenicity of these devices and allowing the safe shortening of DAPT if necessary [8]. Moreover, changes of platelet reactivity on treatment with P2Y12 inhibitors during the acute phase and the following stable period after ACS [9-18] is an additional factor to be considered. The complexity and ever-better understanding of the pathophysiology of ACS, as well as the ever-wider therapeutic possibilities, require a rethinking of the antiplatelet treatment strategy in this clinical setting.

According to the current guidelines, DAPT with a P2Y12 receptor inhibitor and aspirin is recommended for 12 months to reduce adverse thrombotic events [10, $12,19,20]$. DAPT can be modified, its duration can be shortened or extended depending on the patient's ischaemic and bleeding risk, the occurrence of adverse events, comorbidities, co-medications, and drugs availability [12]. Termination of treatment with aspirin after 3-6 months after PCl with stent implantation for ACS should be considered, depending on the balance be- tween bleeding and ischaemic risk [19]. De-escalation of DAPT defined as replacing prasugrel or ticagrelor with clopidogrel may be considered in patients after ACS. De-escalation may be unguided, based solely on clinical judgment or guided by platelet function testing or CYP2C19 genotyping, depending on the patient's risk profile and availability of respective assays [19].

The recommendation regarding the de-escalation strategy based on switching a potent P2Y12 receptor inhibitor to clopidogrel is based on the TOPIC study and the TROPICAL-ACS study $[19,21,22]$. In the TOPIC study switching from prasugrel or ticagrelor to clopidogrel one month after ACS was associated with a net clinical benefit mainly driven by bleeding reduction with an unchanged risk of ischaemic events [21]. The TROPICAL-ACS study showed that de-escalation from prasugrel to clopidogrel guided by platelet function testing was non-inferior to standard treatment with prasugrel at 1 year after percutaneous coronary intervention in terms of net clinical benefit in patients with ACS. However, in the de-escalation group, as much as $39 \%$ of patients required a switch-back to prasugrel due to insufficient platelet inhibition with clopidogrel defined as HPR [22].

The TWILIGHT study tested another de-escalation strategy comparing DAPT with ticagrelor $90 \mathrm{mg}$ b.i.d. and aspirin versus ticagrelor $90 \mathrm{mg}$ b.i.d. alone was assessed [28]. Monotherapy with ticagrelor resulted in substantially less bleeding events than DAPT arm without ischaemic harm [23].

Recently a new antiplatelet de-escalation approach was proposed in the ELECTRA-SIRIO 2 study (Clinical- 
Trials.gov Identifier: NCT04718025; EudraCT number: 2020-005130-15). The study was designed to evaluate the safety and efficacy of ticagrelor dose reduction with or without the continuation of aspirin versus DAPT with standard-dose ticagrelor in ACS patients. The strategy proposed in the ELECTRA-SIRIO 2 study does not require platelet reactivity testing, making de-escalation more feasible for a wide clinical application [24-28]. The study population will comprise 4,500 patients consecutively admitted to the study centres due to ACS, including patients with ST-elevation myocardial infarction, non-ST-elevation myocardial infarction and unstable angina [24]. The intention-to-treat analysis, i.e. with the inclusion of all patients according to the randomly assigned trial group, irrespective of the actual treatment received, is a widely used method in randomized clinical trials, therefore adherence to study medication is a pivotal issue. Poor adherence to the study treatment may lead to serious evaluation bias [29, 30]. The MEDMOTION project involving patients' education, motivation, reminding them to take medications and to attend consecutive medical appointments will be applied to improve adherence to study medication [31-50]. The project includes the diagnosis of study participants concerning their readiness for discharge from the hospital (the Readiness for Hospital Discharge after Myocardial Infarction Scale - RHD-MIS), the risk of non-adherence to the medication (the Adherence in Chronic Diseases Scale, ACDS), and the functioning in disease (the Functioning in Chronic Illness Scale, FCIS). A prespecified sub-analysis of the ELECTRA-SIRIO 2 trial is planned to evaluate the impact of the results of MEDMOTION diagnostic tools on the clinical outcomes [24, 51-59].

The ELECTRA-SIRIO 2 study testing a new approach to treatment de-escalation is expected to provide a new, safer, yet easy-to-apply antiplatelet treatment strategy in a patient after ACS.

\section{References}

1. Budaj A, Yusuf S, Mehta SR, et al. Clopidogrel in Unstable angina to prevent Recurrent Events (CURE) Trial Investigators, Clopidogrel in Unstable Angina to Prevent Recurrent Events Trial Investigators. Effects of clopidogrel in addition to aspirin in patients with acute coronary syndromes without ST-segment elevation. N Engl J Med. 2001 345(7): 494-502, doi: 10.1056/NEJMoa010746, indexed in Pubmed 11519503.

2. Yusuf S, Mehta SR, Zhao F, et al. Clopidogrel in Unstable angina to prevent Recurrent Events Trial Investigators. Early and late effects of clopidogrel in patients with acute coronary syndromes. Circulation. 2003; 107(7): 966-972, doi: 10.1161/01.cir.0000051362.96946.15, indexed in Pubmed: 12600908.

3. Adamski P, Adamska U, Ostrowska M, et al. New directions for pharmacotherapy in the treatment of acute coronary syndrome. Expert Opin Pharmacother. 2016; 17(17): 2291-2306, doi: 10.1080/14656566.2016.1241234, indexed in Pubmed: 27677394.

4. Wallentin L, Becker RC, Budaj A, et al. PLATO Investigators. Ticagrelor versus clopidogrel in patients with acute coronary syndromes. N Engl
J Med. 2009; 361(11): 1045-1057, doi: 10.1056/NEJMoa0904327, indexed in Pubmed: 19717846.

5. Wiviott SD, Braunwald E, McCabe CH, et al. TRITON-TIMI 38 Investigators, TRITON-TIMI 38 Investigators. Evaluation of prasugrel compared with clopidogrel in patients with acute coronary syndromes: design and rationale for the TRial to assess Improvement in Therapeutic Outcomes by optimizing platelet InhibitioN with prasugrel Thrombolysis In Myocardial Infarction 38 (TRITON-TIMI 38). Am Heart J. 2006; 152(4): 627-635, doi: 10.1016/j.ahj.2006.04.012, indexed in Pubmed: 16996826.

6. Navarese EP, Khan SU, James S, et al. Comparative Efficacy and Safety of Oral P2Y Inhibitors in Acute Coronary Syndrome: Network Meta-Analysis of 52816 Patients From 12 Randomized Trials. Circulation. 2020; 142(2): 150-160, doi: 10.1161/CIRCULATIONAHA. 120.046786, indexed in Pubmed: 32468837.

7. Bonaca MP, Bhatt DL, Cohen M, et al. PEGASUS-TIMI 54 Steering Committee and Investigators. Long-term use of ticagrelor in patients with prior myocardial infarction. N Engl J Med. 2015; 372(19): 1791-1800, doi: 10.1056/NEJMoa1500857, indexed in Pubmed: 25773268.

8. Ostrowska M, Kubica J, Adamski P, et al. Stratified Approaches to Antiplatelet Therapies Based on Platelet Reactivity Testing. Front Cardiovasc Med. 2019; 6: 176, doi: 10.3389/fcvm.2019.00176, indexed in Pubmed: 31850373

9. Adamski P, Buszko K, Sikora J, et al. Determinants of high platelet reactivity in patients with acute coronary syndromes treated with ticagrelor. Sci Rep. 2019; 9(1): 3924, doi: 10.1038/s41598-019-40628-0, indexed in Pubmed: 30850677

10. Valgimigli M, Bueno $H$, Byrne RA, et al. ESC Scientific Document Group, ESC Committee for Practice Guidelines (CPG), ESC National Cardiac Societies. 2017 ESC focused update on dual antiplatelet therapy in coronary artery disease developed in collaboration with EACTS: The Task Force for dual antiplatelet therapy in coronary artery disease of the European Society of Cardiology (ESC) and of the European Association for Cardio-Thoracic Surgery (EACTS). Eur Heart J. 2018; 39(3): 213-260, doi: 10.1093/eurheartj/ehx419, indexed in Pubmed: 28886622

11. Kubica J, Adamski P, Niezgoda P, et al. Prolonged antithrombotic therapy in patients after acute coronary syndrome: A critical appraisal of current European Society of Cardiology guidelines. Cardiol J. 2020; 27(6): 661-676, doi: 10.5603/CJ.a2020.0132, indexed in Pubmed: 33073857.

12. Kubica J, Adamski P, Paciorek P, et al. Treatment of patients with acute coronary syndrome: Recommendations for medical emergency teams: Focus on antiplatelet therapies. Updated experts' standpoint. Cardiol J. 2018; 25(3): 291-300, doi: 10.5603/CJ.a2018.0042, indexed in Pubmed: 29671864

13. Kubica J, Kubica A, Jilma B, et al. Impact of morphine on antiplatelet effects of oral P2Y12 receptor inhibitors. Int J Cardiol. 2016; 215: 201208, doi: 10.1016/j.jijcard.2016.04.077, indexed in Pubmed: 27128531.

14. Kubica J, Adamski P, Ostrowska M, et al. Influence of Morphine on Pharmacokinetics and Pharmacodynamics of Ticagrelor in Patients with Acute Myocardial Infarction (IMPRESSION): study protocol for a randomized controlled trial. Trials. 2015; 16: 198, doi: 10.1186/s13063015-0724-Z, indexed in Pubmed: 25925591.

15. Kubica J, Adamski P, Ostrowska M, et al. Morphine delays and attenuates ticagrelor exposure and action in patients with myocardial infarction: the randomized, double-blind, placebo-controlled IMPRESSION trial. Eur Heart J. 2016; 37(3): 245-252, doi: 10.1093/eurheartj/ehv547, indexed in Pubmed: 26491112

16. Hobl EL, Reiter B, Schoergenhofer C, et al. Morphine decreases ticagrelor concentrations but not its antiplatelet effects: a randomized trial in healthy volunteers. Eur J Clin Invest. 2016; 46(1): 7-14, doi: 10.1111/eci.12550, indexed in Pubmed: 26449338.

17. Kim HK, Kubica J, Jeong YH. Ticagrelor vs Clopidogrel for Patients With Acute Coronary Syndrome Undergoing Percutaneous Intervention. JAMA. 2021; 325(9): 890, doi: 10.1001/jama.2020.26020, indexed in Pubmed: 33651086.

18. Kubica J, Kubica A, Jilma B, et al. Impact of morphine on antiplatelet effects of oral P2Y12 receptor inhibitors. Int J Cardiol. 2016; 215: 201208, doi: 10.1016/j.jicard.2016.04.077, indexed in Pubmed: 27128531.

19. Collet JP, Thiele H, Barbato E, et al. ESC Scientific Document Group 2020 ESC Guidelines for the management of acute coronary syndromes in patients presenting without persistent ST-segment elevation. Eur Heart J. 2020 [Epub ahead of print], doi: 10.1093/eurheartj/ehaa575, indexed in Pubmed: 32860058.

20. Navarese EP, Wernly B, Lichtenauer M, et al. Dual vs single antiplatelet therapy in patients with lower extremity peripheral artery disease A meta-analysis. Int J Cardiol. 2018; 269: 292-297, doi: 10.1016/j. ijcard.2018.07.009, indexed in Pubmed: 30045826. 
21. Deharo P, Quilici J, Camoin-Jau L, et al. Benefit of switching dual antiplatelet therapy after acute coronary syndrome: the TOPIC (timing of platelet inhibition after acute coronary syndrome) randomized study. Eur Heart J. 2017; 38(41): 3070-3078, doi: 10.1093/eurheartj/ehx175, indexed in Pubmed: 28510646.

22. Sibbing D, Aradi D, Jacobshagen C, et al. Guided de-escalation of antiplatelet treatment in patients with acute coronary syndrome undergoing percutaneous coronary intervention (TROPICAL-ACS): a randomised, open-label, multicentre trial. The Lancet. 2017; 390(10104): 1747-1757, doi: 10.1016/s0140-6736(17)32155-4.

23. Mehran R, Baber U, Sharma S, et al. Ticagrelor with or without Aspirin in High-Risk Patients after PCI. New England Journal of Medicine. 2019; 381(21): 2032-2042, doi: 10.1056/nejmoa1908419.

24. Kubica A, Adamski P, Baczkowska A, et al. The rationale for Multileve Educational and Motivational Intervention in Patients after Myocardial Infarction (MEDMOTION) project is to support multicentre randomized clinical trial Evaluating Safety and Efficacy of Two Ticagrelor-based De-escalation Antiplatelet Strategies in Acute Coronary Syndrome (ELECTRA - SIRIO 2). Medical Research Journal. 2020; 5(4): 244-249, doi: 10.5603/mrj.a2020.0043.

25. Kubica J, Adamski P, Buszko K, et al. Platelet inhibition with standard vs. lower maintenance dose of ticagrelor early after myocardial infarction (ELECTRA): a randomized, open-label, active-controlled pharmacodynamic and pharmacokinetic study. Eur Heart J Cardiovasc Pharmacother. 2019; 5(3): 139-148, doi: 10.1093/ehjcvp/pvz004, indexed in Pubmed: 30689800.

26. Kubica J, Adamski P, Buszko K, et al. Rationale and Design of the Effectiveness of LowEr maintenanCe dose of TicagRelor early After myocardial infarction (ELECTRA) pilot study. Eur Heart J Cardiovasc Pharmacother. 2018; 4(3): 152-157, doi: 10.1093/ehjcvp/pvx032. indexed in Pubmed: 29040445.

27. Navarese EP, Khan SU, Kołodziejczak M, et al. Comparative Efficacy and Safety of Oral P2Y Inhibitors in Acute Coronary Syndrome: Network Meta-Analysis of 52816 Patients From 12 Randomized Trials. Circulation. 2020; 142(2): 150-160, doi: 10.1161/CIRCULATIONAHA.120.046786, indexed in Pubmed: 32468837.

28. Buszko K, Obońska K, Michalski P, et al. The Adherence Scale in Chronic Diseases (ASCD). The power of knowledge: the key to successful patient - health care provider cooperation. Medical Research Journal. 2016; 1(1): 37-42, doi: 10.5603/mri.2016.0006

29. Kubica J, Jaguszewski M. ISAR-REACT 5 - What have we learned? Cardiol J. 2019; 26(5): 427-428, doi: 10.5603/CJ.a2019.0090, indexed in Pubmed: 31536136.

30. Kubica J, Jaguszewski M. Ostrowska M, et al. Creative scientific dispute - different points of view on the protocol and execution of the ISAR-REACT 5 trial. Medical Research Journal. 2020; 5(1): 41-45, doi: 10.5603/mri.a2020.0008

31. Kosobucka A, Michalski P, Pietrzykowski $\measuredangle$, et al. Adherence to treatment assessed with the Adherence in Chronic Diseases Scale in patients after myocardial infarction. Patient Prefer Adherence. 2018: 12 333-340, doi: 10.2147/PPA.S150435, indexed in Pubmed: 29551891

32. Kosobucka A, Michalski P, Pietrzykowski $€$, et al. The impact of readiness to discharge from hospital on adherence to treatment in patients after myocardial infarction. Cardiol J. 2020 [Epub ahead of print], doi: 10.5603/CJ.a2020.0005, indexed in Pubmed: 32037501

33. Pietrzykowski Ł, Michalski P, Kosobucka A, et al. Medication adherence and its determinants in patients after myocardial infarction. Sci Rep. 2020; 10(1): 12028, doi: 10.1038/s41598-020-68915-1, indexed in Pubmed: 32694522.

34. Kubica A, Kosobucka A, Michalski P et al. The Adherence in Chronic Diseases Scale - a new tool to monitor implementation of a treatment plan. Folia Cardiologica 2017;12:19-26, DOI: 10. 5603/FC. ; 2016 0000, doi: 10.5603/FC.2016.0000.

35. Kubica A, Kochman W, Bogdan M, et al. The influence of undergone percutaneous coronary interventions, and earlier hospitalizations with myocardial infarction on the level of knowledge and the effectiveness of health education in patients with myocardial infarction. Advances in Interventional Cardiology. 2009; 5: 25-30. doi: 10.1016/j.amjcard.2013.05. 064, indexed in Pubmed. ; 23827404, doi: 10.1016/j. amjcard.2013.05.064

36. Kubica A, Obońska K, Fabiszak T, et al. Adherence to antiplatelet treatment with P2Y12 receptor inhibitors. Is there anything we can do to improve it? A systematic review of randomized trials. Curr Med Res Opin. 2016; 32(8): 1441-1451, doi: 10.1080/03007995.2016.1182901, indexed in Pubmed: 27112628.

37. Adamski P, Ostrowska M, Navarese EP, et al. Pharmacodynamic and clinical efficacy of reduced ticagrelor maintenance doses in patients with coronary artery disease. Curr Med Res Opin. 2021; 37(2): 195-206 doi: 10.1080/03007995.2020.1854207, indexed in Pubmed: 33211543

38. Kubica A. Self-reported questionnaires for a comprehensive assessment of patients after acute coronary syndrome. Medical Research Journal. 2019; 4(2): 106-109, doi: 10.5603/mri.a2019.0021.

39. Michalski P, Kasprzak M, Siedlaczek M, et al. The impact of knowledge and effectiveness of educational intervention on readiness for hospital discharge and adherence to therapeutic recommendations in patients with acute coronary syndrome. Medical Research Journal. 2020, doi: 10.5603/mrj.a2020.0023

40. Kubica A. Rationale of cardiopulmonary resuscitation training as an element of multilevel educational and motivational project (MEDMOTION). Disaster and Emergency Medicine Journal. 2020, doi: 10.5603/demj.a2020.0017.

41. Kubica A, Bączkowska A. Uzasadnienie interwencji motywacyjnych jako kluczowego elementu projektu wielopoziomowej edukacji i motywacji u pacjentów z zawałem serca (MEDMOTION). Folia Cardiologica. 2020; 15(1): 6-10, doi: 10.5603/fc.2020.0003.

42. Buszko K, Pietrzykowski $Ł$, Michalski P, et al. Validation of the Functioning in Chronic Illness Scale (FCIS). Medical Research Journal. 2018; 3(2): 63-69, doi: 10.5603/mrj.2018.0011.

43. Pietrzykowski $Ł$, Michalski P, Kosobucka A, et al. Knowledge about health and disease in obese patients after myocardial infarction. An observational study. Medical Research Journal. 2018; 2(4): 135-140, doi: 10.5603/mrj.2017.0018.

44. Kubica A, Kosobucka A, Michalski P, et al. Self-reported questionnaires for assessment adherence to treatment in patients with cardiovascular diseases. Medical Research Journal. 2018; 2(4): 115-122, doi: 10.5603/mrj.2017.0015

45. Kubica A, Gruchała M, Jaguszewski M, et al. Adherence to treatment - a pivotal issue in long-term treatment of patients with cardiovascular diseases. An expert standpoint. Medical Research Journal. 2018; 2(4) 123-127, doi: 10.5603/mri.2017.0016.

46. Kosobucka A Kasprzak M, Michalski P et al Relation of the Readiness for Hospital Discharge after Myocardial Infarction Scale to socio-demographic and clinical factors. An observational study. Medical Research Journal. 2018; 3(1): 32-37, doi: 10.5603/mri.2018.0006.

47. Michalski P, Kosobucka A, Pietrzykowski $\measuredangle$, et al. Effectiveness of therapeutic education in patients with myocardial infarction. Medical Research Journal. 2018; 2(3): 89-96, doi: 10.5603/mrj.2017.0011.

48. Buszko K, Kosobucka A, Michalski P, et al. The readiness for hospita discharge of patients after acute myocardial infarction: a new self-reported questionnaire. Medical Research Journal. 2017; 2(1): 20-28 doi: 10.5603/mri.2017.0004.

49. Winter MP, Koziński M, Kubica J, et al. Personalized antiplatelet therapy with P2Y12 receptor inhibitors: benefits and pitfalls. Postepy Kardiol Interwencyjnej. 2015; 11(4): 259-280, doi: 10.5114/pwki.2015.55596, indexed in Pubmed: 26677375

50. Kubica A, Sinkiewicz W, Szymański P, et al. Edukacja zdrowotna w chorobach układu kraż̇enia - możliwości i zagrożenia. Folia Cardiologica Excerpta. 2007; 2: 177

51. Kubica A. Wybrane problemy prewencji wtórnej u chorych po incydentach wieńcowych. Folia Cardiologica Excerpta. 2008; 3: 366.

52. Kubica A, Obońska K, Kasprzak M, et al. The impact of metabolic syndrome on the antiplatelet effect of clopidogrel and aspirin in patients with acute coronary syndrome. Folia Med Copernicana. 2014; 2: 66-72.

53. Kubica A, Kasprzak M, Obońska K et al. Impact of health education on adherence to clopidogrel and clinical effectiveness of antiplatelet treatment in patients after myocardial infarction. Medical Research Journal. 2016; 3(4): 154-159, doi: 10.5603/fmc.2015.0010.

54. Kubica A, Kasprzak M, Obońska K, et al. Discrepancies in assessment of adherence to antiplatelet treatment after myocardial infarction. Pharmacology. 2015; 95(1-2): 50-58, doi: 10.1159/000371392, indexed in Pubmed: 25592409

55. Kubica A. Problems of long-term antiplatelet therapy after coronary stent implantation. Advances in Interventional Cardiology 2009; 5: 158-161.

56. Kubica A, Grześk G, Sinkiewicz W, et al. Compliance, concordance, adherence in chronic therapy. Folia Cardiol Excerpta. 2010; 5: 54-57.

57. Kubica A, Kasprzak M, Siller-Matula J, et al. Time-related changes in determinants of antiplatelet effect of clopidogrel in patients after myocardial infarction. Eur J Pharmacol. 2014; 742: 47-54, doi: 10.1016/j. ejphar.2014.08.009, indexed in Pubmed: 25199965.

58. Kubica A Obońska $K$, Kasprzak M et al. Prediction of high risk of non-adherence to antiplatelet treatment. Kardiol Pol. 2016; 74(1) 61-67, doi: 10.5603/KP.a2015.0117, indexed in Pubmed: 26101025

59. Kubica A. Collaboration with the patient - a basic condition of therapy effectiveness in coronary artery disease. Chor. Serca Nacz. 2009; 6: 131-134. 